This article has been scanned by iThenticat No plagiarism detected

Volume 3, Issue 6, December 2021

p. $458-466$

\title{
A COMPILATION/EVALUATION ON NICKNAMES USED IN HATAY-KUMLU DISTRICT
}

http://dx.doi.org/10.47832/2757-5403.6-3.34

\begin{abstract}
:
In this study, nicknames, which are an important symbol in recognizing and distinguishing people living together more easily, are discussed in the example of Hatay-Kumlu. While giving a nickname, features such as physical characteristics, state and movements, behaviors, social status, economic situation, occupation, character, ethnic origin play a role. As a result, with this study, it is aimed to reveal the nicknames, which have an important function in preserving the culture in question and transferring it to future generations, in the example of Kumlu district of Hatay.
\end{abstract}

Key words: Hatay-Kumlu Nicknames, Nicknames in Turkish, Nicknames, The Place of Nicknames in Turkish Language, Compilation.

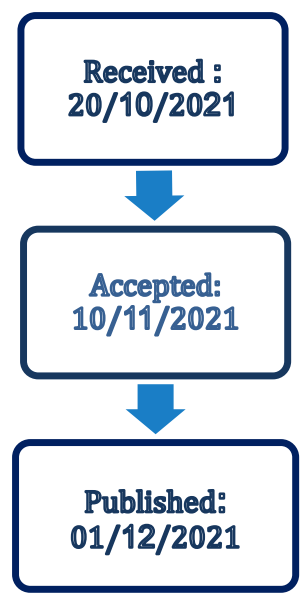

\footnotetext{
${ }^{1}$ Dr., Turkey, ahmedsafak@hotmail.com, https://orcid.org/0000-0003-0088-3010
}

Copyright (C) Published by IJHER Journal, www.ijherjournal.com Rimar Academy, Fatih, Istanbul, 34093 Turkey 


\title{
HATAY-KUMLU İLÇESINDE KULLANILAN LAKAPLAR ÜZERİNE BİR DERLEME/DEĞERLENDİRME
}

\begin{abstract}
Ahmet ŞAFAK
$\ddot{O} z$

$\mathrm{Bu}$ çalışmada, bir arada yaşayan insanları daha kolay tanımak ve birbirinden ayırt etmede önemli bir simge olan lakaplar, HatayKumlu örneğinde ele alınmıştır. Lakap verilirken fiziksel özellikler, hal ve hareketler, davranıslar, sosyal statü, ekonomik durum, meslek, karakter, etnik kökeni gibi özellikleri rol oynar. Sonuç olarak, bu çalışma ile söz konusu kültürün korunması ve gelecek kuşaklara aktarımında önemli bir işleve sahip olan lakapların Hatay'ın Kumlu ilçesi örneğinde ortaya konulması amaçlanmıştır.

Anahtar Kelimeler: Hatay-Kumlu Lakapları, Türkçe'de Lakaplar, Takma Ad, Lakapların Türk Dilindeki Yeri, Derleme.
\end{abstract}

\section{1-Giriş}

Her toplumun toplum yapısı, gelenek görenek ve anlayışına uygun birçok uygulamaları mevcuttur. Ad verme geleneği de bu uygulamaların başında gelir. Tabiattaki her maddenin bir isminin olduğu gibi her bireyin de kendine ailesi tarafından konulmuş olan bir adı vardır. Bireylerin tanınması, birbirlerinden ayırt edilmesi, başka kişilerle karıștırılmaması için aileler çocuklarına farklı farklı isimler verirler. Verilen bu isimler o kişi tarafından ömrü boyunca kendisine hitap edilmesi için kullanılan kelimelerdir. İnsanlık tarihinde ilk verilen adlar ve ad verme şekilleri birbirlerine benzer olmakla beraber sonraki dönemlerde toplumların kültürleri farklılaşmaya başlayınca ad verme gelenekleri de toplumdan topluma farklılık gösterir hale gelmiştir. Bir kimseye, bir aileye kendi adından ayrı olarak sonradan takılan, o kimsenin veya o ailenin bir özelliğinden kaynaklanan ad (www.tdk.gov.tr, erişim tarihi: 20.12.2020). Bir kimseye asıl adından ayrı olarak sonradan takılan ikinci ad; şeref pâyesi; halife ve sultanların hâkimiyet alâmeti. (www.islamansiklopedisi.org.tr, erişim tarihi: 20.12.2020).

Kültürün önemli unsurlarından olan dil, bir yandan toplumun hakikatlerini yansitırken, diğer yandan kültürün yeniden meydana gelmesini ve devamını sağlar (Türk, 2019: 320). Dil, bir toplumun düşünce yapısını gösteren, milleti millet yapan, insan ile toplum arasındaki bağı sağlayan en güçlü kültür öğesidir (Türk, 2017: 786). Türk kültürünün tarihî sürecinde çocuğa verilen adın, onun kaderini de belirleyeceği inancıyla çok önemsenmiș ve ad seçilirken büyük bir itina gösterilmiştir. Akrabalık ile ilgili sözcükler dilin temel söz varlığı içerisinde yer alır.Türk kültürünü yansıtan önemli eserlerden Dîvânü Lügâti't-Türk'te Kâşgarlı Mahmut, Türk aile yapısını yansıtan akrabalık adlarından bahsetmiştir. (Koç, 2020: 267). Türkler yaşadıkları dönemin özellikleri ve yaşayış şekillerine göre çocuklarına dönem dönem değişik adlar vermişlerdir. Bu da o dönemin sosyal, siyasi ve aynı zamanda ekonomik yapısıyla da ilgili olmuştur (Türktaş. 2019: 36). Türk destanlarında kahramanın doğumundan sonra ona adının verilmesine artık sıra gelmiştir. Çocuğa adının verilmesi, çocuğun korunması, sosyal hayatta başarılı olabilmesi için ad koyma motifi alınan tedbirlerden biriydi. Ad, kişinin karakterinin oluşumunda önemli bir yere sahip olduğu inancından dolayı çocuğa gelişigüzel ad konuluyordu; toplumdaki yerini ve başarısını etkileyecek bir ad vermeye dikkat edilirdi (Şafak, 2017: 261). Yaşamla edebiyat arasındaki yapıya eşdeğer olarak, çağın yaşayışını, felsefesini, dünya görüşünü ve zevkini takip eder (Türk, 2021: 137). 


\section{Lakaplar}

Lakaplar kişileri kendi isminden farklı olarak tanıtan sonradan konan isimlerdir. $\mathrm{Bu}$ lakaplar genellikle o kişinin belirgin bir özelliğinden (görünüş, konuşma şekli, davranış, fiziksel özellik vb.) dolayı konmuş isimlerdir. Kişilere takılmış olan lakaplar dışında ailelere ve topluluklara da genel olarak lakaplar verilmisstir. Bunlar genellikle soy veya ailenin bir büyügünün (anne-baba) adı olan isimleri lakap olarak kullanmışlar ya da 1rk, aşiret ya da mensup olduğu toplumun ismini kullanarak bir lakap oluşturulmuş isimlerdir. Ayrica bir arada yaşayan insanları daha kolay tanımada ve birbirinden ayırt etmede önemli bir simge olan lakapların kişi adlarıyla birlikte yaygın olarak kullanıldığı tespit edilmiştir

Lakap ve unvanlar Türk kültüründe oldukça önemli bir yere sahiptir. Günümüzde dahi birçok kişi lâkapları ile anılmaktadır. Lâkaplar kişinin fizikî, ruhsal, sosyolojik, soy-sop, mesleki olarak, çeşitli karakteristik özelliklerinden hareketle toplumdaki yerini ayırt etmeyi kolaylaştıran bir unsurdur. Lakap kullanımı, resmî kayıt sisteminden önceki dönemlerde kişilerin tanınmasına yönelik önemli bir fonksiyonu da üstlenmiştir. Lâkap ve unvanları ele alırken, ait olduğu zaman dilimi ve bu zaman diliminin sosyal bağlamı da mutlaka göz önünde tutulmalıdır (Güllüdağ-Baş, 2019: 73).

Unvan ise, bir kimsenin memuriyet rütbesini ve görevini belirten söz yani lakaptır (Özaydın, 2012: 163). Kişilere atfedilen unvanlar ulusların yaşam biçimlerini yansıtır. Bir sosyal yapı içerisinde icra edilen unvan ve bu unvanlara verilen öneme bakılarak o toplumun kültürel değerleri hakkında düşünce sahibi olunabilir

Bir kimsenin derecesini, rütbesini belirleyen söz yani lakaplardır. Kişilere atfedilen lakaplar kişilerin sosyal statülerine bakılarak adlandırmaya gidilir. Haliyle unvan veya lakaplara bakılarak o toplumun kültürel değerlerine hakkında fikir sahibi olunabilir (Türk, 2020: 263) Lakaplar yazılı ve sözlü kültürde kullanılarak günümüze kadar farklı şekil ve işlevlerde gelmiştir. Lakapların çok eski dönemlerden beri kullanıldığı tarihî kaynaklardan hareketle öğrenilmektedir (Bulukgiray, 2021: 64). 21 Haziran 1934 tarihinde Medeni Kanun'un ve Dil İnkılabının parçası olarak kabul gören Soyadı Kanunu'na değin Türkiye'de kişiler, baba soyadı yahut da lakaplarla tanınmakta idi. Devlet düzeni yanında, toplumdaki her bir birey, kendi kişiliği ve yaptığı işten dolayı tanınmayı kolaylaştırıcı isimler ve zamanla lâkaplar almaya başlamıştır (Akçam, 2015: 192). Osmanlı İmparatorluğu'nun çatısı altındaki halk, vatandaş değil, tebaa statüsünde olduğu için çağdaş düzeydeki bireysel hak ve özgürlükler oldukça geç olgunlaşmıştır. Bu maksatla atılan adımlar arasında yer alan Soyadı Kanunu ile insanları birbirinden ayırt etme, lakaplarla değil soyadları ile sağlanacaktır. Günümüzde halk nezdinde de yaygınlık oranı gittikçe azalmış olan lakapların toplumsal boyutunun aksine özellikle Anadolu'nun küçük yerleşim birimlerinde ve insan ilişkilerinin daha yoğun ve sıkı olduğu mahallelerde kişilerin bireysel özelliklerine bağlı olan kişisel boyutu yaygın bir şekilde devam etmektedir (Parlak Kalkan, 2020: 201).

Lakaplar konusu için bilenen kalemlerin anlattıklarını ve verdikleri tarifleri şu lakap tanımı üzerinde özetlemek mümkündür: Asıl Ad'a sonradan eklenen ve kişinin her hangi bir özelliğinden dolayı verilen isimdir (Boyraz, 1988: 109). Lakap takma insanoğlunun yaratılışıla birlikte ortaya çıkan bir süreçtir. Lakap önceleri "nebez" kelimesinin anlamını karşılayacak şekilde kullanılır. Nebez, "bir kimseye gizli kalmasını istediği bir ayıbıyla hitap etmek" anlamına gelir (Sevinç, 2019: 312). Lakaplar konusundaki bir diğer husus ise sülaleye verilen adlandırmaların lakap olarak kabul edilip edilmemesidir. Bu konuda da kriterimiz yine kaynak şahısların bilgileri, sahada nasıl kullanıldığı ve lakap işlevini taşıyıp taşımadığı gibi hususlardır. Sülale lakaplarının büyük bir kısmı ailedeki bir kişinin lakabından ya da adından hareketle ortaya çıkmıştır (Atlı, 2017: 104).

Lakapların yapısı dikkate alındığında, bir kısmının bir kişinin adından bağımsız olarak başka bir isim verilmesi veya mevcut isme ek veya kelime ilavesi yapılarak kullanılması 
şeklinde iki kullanım görülmektedir. Kişinin ismine ek veya ikinci bir kelime ilave ederek lakap takma veya kullanım da iki farklı şekilde oluşmaktadır. Birincisi, kişinin özgün ismine can, bek gibi unvanlar ve varyantları ile sevgi, şefkat, acıma gibi duyguları ifade eden küçültme ekleri eklemek suretiyle oluşurken, ikincisinde özgün ismin ilk hecesi alınarak veya ismin son hecesi veya hecedeki bazı sesler atılarak kelime ilave edilmekte veya ek getirilmektedir. Elbette bu yapıların bir kısmı ismin özgün şeklini oluştururken bir kısmı sadece kullanımda ortaya çıkan şekillerdir (Koraş- Shaikenova, 2021: 223).

\section{Kumlu İlçesi}

Kumlu ilçesi Hatay il merkezine 40 kilometre mesafede Amik Ovası'nın ortasında düzlük bir arazi üzerine kurulmuştur. Kuzeyinde Kırıkhan ilçesi, batısında Antakya, güneyinde Reyhanlı ilçesiyle çevrilmiş olup, doğusunda 22 kilometrelik Suriye hududu olan bir sinır ilçesidir. Denizden ortalama yüksekliği 95 metre olan Kumlu, iklim olarak Akdeniz iklimi özelliğini taşımaktadır. İlçenin yüzölçümü 223 kilometrekaredir. Amik ovasının merkezinde bulunan Kumlu ilçesi 1945 yılından önce Amik Gölü'nün istilası altında çeşitli sazlıklara kaplı bataklık bir yer iken, 1945 yılında iskan yeri olarak tahsis edilmesinden sonra Killik köyü olarak yerleşim yeri olmuştur. Daha sonra çevrenin büyük köylerinde yaşayan topraksız vatandaşlar gelip bu yere yerleşmişlerdir (Şafak, 2021: 229).

\section{Yöntem}

Bu çalışma, betimsel bir araştırma olup 2020 yılında muhtelif zamanlarında Hatay ilinin Kumlu ilçe 3 mahallesinde özellikle yerli halkın yaşadığı Cumhuriyet, Fevzi Çakmak, Gökçeoğlu mahallelerinden ikamet eden 21 kaynak kişi aracılığıyla kullanımda olan ya da daha önce kullanılmış olup sonrasında çocuklarına sirayet eden lakaplar derlenmiş olup, belirli anlam ve özelliklere göre sınıflandırılmıştır.

\section{Yaptığı işten ya da meslekten dolayı verilmiş olan lakaplar}

$\begin{array}{ll}\text { Ahmet Usta } & \text { Garajcı Mustafa } \\ \text { Bastacı Yaşar } & \text { Günnükçü } \\ \text { Bekçi Tahir Teter } & \text { Hallak (Arapçada berber } \\ \begin{array}{l}\text { Cücükçü (Faizci) } \\ \text { Çoban Mağmor }\end{array} & \text { anlamırna gelir) } \\ \text { Demirci Hüseyin } & \text { Hamit Çavuş } \\ \text { Dükkenci } & \text { İnneci (Sağllkçı) İsmail } \\ \text { Hüseyin } & \text { Kasap Hasan } \\ \text { Fırıncı Mehmet } & \text { Kaymakçı (Dondurmac1) } \\ \text { Foto Hasan } & \text { Apo } \\ \text { Ganevüzcü Zekeriya } & \text { Kaynakçı Kemal } \\ & \text { Kuyucu Halil }\end{array}$

Lastikçi İbo Mezarc1 Mahmut Muhtar Murat Müezzin Nahırci Hasan Nohutçu Ado Postac1 Kemal Sucu Mammat Tavukçu Hüseyin Terzi Hasan

Fiziksel özellik, eksiklik ya da görünüşündeki farklılıklardan dolayı verilmiş lakaplar

$\begin{array}{lll}\text { Ahraz(Sağır-Dilsiz kimse) } & \text { Çapar Hilel } & \text { Gözugöv Mammat } \\ \text { Ayı Mahmut } & \text { Çilo } & \text { Guttuk (Kisa) Bostan } \\ \text { Bedir Culluk } & \text { Çolak Bekir } & \text { Köse Hasan } \\ \text { Beton Fatma } & \text { Dev Ali } & \text { Jilet Mecit } \\ \text { Biyıklı Süleyman } & \text { Dişi büyük Ali } & \text { Kara Duran } \\ \text { Boynu Eğri } & \text { Fodul (Kısa, çelimsiz) } & \text { Kekeç (Kekeme) Rifat } \\ \text { Boynu Kırmızı Mustafa } & \text { Gemik Nuri } & \text { Kel Vahit } \\ \text { Bozo Hüseyin } & \text { Götü Büyük Merem } & \text { Kemçik } \\ \text { Ceketsiz Fevzi Kartaca } & \text { Gözlüklü Abdurrahman } & \text { Kerrik Kulakli }\end{array}$


A COMPILATION/EVALUATION ON NICKNAMES USED IN HATAY-KUMLU

DISTRICT

K1llı Hasan

Kirmızı Hasan

Kize Kemal

Kirli Abit

Kirpi Hikmet

Kurbağa Hasan

Kuru Bostan

Küflu Mehmet

Kör Reşit
Lopçu (Şişko-Çok Yiyen)

Memet

Mucuk Enver

Öküz Ali

Ötürekli Ötmen

Sefil Ali

Siçan Yilmaz

Sidikli Halil

Su İti Mehmet

\author{
Şaşı Halit \\ Tit Ali \\ Titrek Ötmen \\ Topal Diyep \\ Toppuğu Büyük İsa \\ Uzun Arif \\ Ziba (İri-büyük) Halil
}

Karakter ya da farklı bir özelliğinden dolayı verişmiş olan lakaplar

$\begin{array}{lll}\text { Akkır } & \text { Hintık Murat } & \text { Şeker Memet } \\ \text { Ali Celep } & \text { Kirt } & \text { Telli Zeynep } \\ \text { Cirt İbo } & \text { Kize Kemal } & \text { Zehir } \\ \text { Cins Mehmet } & \text { Mirrık } & \text { Zombo Murat } \\ \text { Çamır Abdurrahman } & \text { Oğraklı Ahmet } & \\ \text { Çeddep (Arapçada } & \text { Osurakçı̇lhan } & \\ \text { Yalancı anlamında) } & & \\ \begin{array}{l}\text { Deli Mehamet } \\ \text { Gevur Ali (Rai Arapça }\end{array} & & \\ \text { Hasan Rei (Roban demek) } & & \\ \text { Çoban } & & \end{array}$

Soy, sülale, aile gibi aidiyet bildiren lakaplar

$\begin{array}{ll}\text { Abbutlar } & \text { Camuzcular } \\ \text { Amiriyeler } & \text { Cirebisler } \\ \text { Temmolar } & \text { Çellolar } \\ \text { Anişeler } & \text { Doneler } \\ \text { Apeler } & \text { Gessumlar } \\ \text { Binasitler } & \text { Giredolar } \\ \text { Belleşeler } & \text { Hamidolar } \\ \text { Beşirler } & \text { Hamişler } \\ \text { Boyrazlar/Poyrazlar } & \text { İliller }\end{array}$

\begin{abstract}
Metcolar
Sattuflar

Simolar

Temmolar

Yağlilar

Yedi Deliler

Zeynebeller

Zoriler
\end{abstract}

Anne ve baba ismi eklenerek verilmiş lakaplar

$\begin{array}{lll}\text { Abit Haco } & \text { Ali Gülo } & \text { Mehamet Topo } \\ \text { Abit İsa } & \text { Azzet Ali Cumo } & \text { Memet Aşo } \\ \text { Ahmet Billo } & \text { Cemil Keno } & \text { Mistık Hamo } \\ \text { Ahmet Cennet } & \text { Cemil Kermo } & \text { Ötmen Allüs } \\ \text { Ahmet Emo } & \text { Halil Beşir } & \text { Reşo Duman } \\ \text { Ahmet Eşeli } & \text { Halil Sahabe } & \text { Süleyman Mağmik } \\ \text { Ahmet Heyro } & \text { Hüseyin Duran } & \text { Süleyman Suphi } \\ \text { Ahmet Meçço } & \text { İsmet Temmo } & \text { Ubeyt Leylo } \\ \text { Ahmet Zeynebe } & \text { Kamil Zahra } & \\ \text { Ali Allo } & \text { Mehamet Fattume } & \end{array}$

Soy, sülale, aile gibi aidiyet bildiren lakaplar

Çerkez Hoca

Kürt Reşit

Köylü

Aptal Cengiz

Arap Ali 
Gelmiş olduğu yerden (Köy, Kasaba, İlçe, İl, vb.) dolayı verilmiş lakaplar

Ardahan Cuma

Elbistanl1 Hac1

Guserli Hüseyin

Hacc1 Allo
İdo Garbi

Koreli Seydi

Merdinli

Muhummet Havas
Ötmen Killik

Şarklı Beşir

Urfalı Abit

Tek isim olarak verilmiş lakaplar

\begin{tabular}{|c|c|c|}
\hline Abat (Mustafa) & Gille Nuri & Merğe \\
\hline Abiler (İkizler) & Ginno & Miçce \\
\hline Acem & Ginno Ahmet & Miçcirık \\
\hline Adik & Giç Hüseyin & Mirdik \\
\hline Alloke & Girnak Hasan & Momber Mehmet \\
\hline Alloş & Gorbi Memet & Muho \\
\hline Ammo & Gözo Cuma & Muşo \\
\hline Azzik & Haddura & Mülo \\
\hline Babule Derviş & Hafiz & Nebo \\
\hline Baho İbrahim & Hamede & Nono \\
\hline Barho & Hamit Tavuk & Omo \\
\hline Bayo & Hammut & Pat Yusuf \\
\hline Bebe Huseyin & Hammut gazale & Patraş Hasan \\
\hline Becek Hasan & Hamo Cepker & Pihpih \\
\hline Beğbeğ İbrahim & Hanif Şaşo & Reşido \\
\hline Beğbo & Hasan Dürzi & Rişko \\
\hline Bey & Hasan Mede & Saddam Bülent \\
\hline Bezzet & Haske & Samuray Ahmet \\
\hline Bışk Derviş & Hasse & Sattuf \\
\hline Borane & Hayder Horo & Sekiz \\
\hline Ceco & Hazzum & Selho \\
\hline Cuma Öne & Heşşo & Siçtım Necdet \\
\hline Cumuk Mehmet & Hezere Mehmet & Sirım Mustafa \\
\hline Çaho & Histo & Somun \\
\hline Çiko & Hişto & Sümer \\
\hline Çomo & Hirdo & Şakkulo \\
\hline Darı Faruk & Hurma & Şamrel \\
\hline Debbur Garip & Hümpo & Şemso \\
\hline Dido Ahmet & Hürçik & Ş1hlı \\
\hline Dilo & Hüsencik & Takke Ahmet \\
\hline Dübeş Hüseyin & İto Turan & Tatvan \\
\hline Dübüs Hüseyin & Kartal Yusuf & Tavuk \\
\hline Ede & Keho & Tencirli \\
\hline Edom & Keko & Teymen \\
\hline Emzik Ahmet Kırar & Kepik & Tiraş Mehmet \\
\hline Epço & Kerno Celal & Tirre Uğur \\
\hline Garrut & Kertrez Ekrem & Tiyba \\
\hline Geber & Kezo & Tivis Memet \\
\hline Geşgüş & Maya & Uççoz Mustafa \\
\hline G1lay & Meme & Ufo \\
\hline
\end{tabular}


A COMPILATION/EVALUATION ON NICKNAMES USED IN HATAY-KUMLU

DISTRICT

$\begin{array}{lll}\text { Umme } & \text { Vebstır Cengiz } & \text { Yeyeler } \\ \text { Ülük } & \text { Vit Hüseyin } & \end{array}$

Arapçadan geçen abu (babası) anlamında kullanılan lakaplar

Abu Hamit

Abu Tiz

Adı, Soyadı ya da unvanı kısaltılarak yapılmış olan lakaplar

Ahmet Kadi

Tanınmış bir şahsa benzetilerek takılmış lakaplar

Lusi Maykıl Hüseyin

Maharyos Megi

Bir isimden sonra gelen lakaplar

Abdo Karto

Abit Asskar

Ahmedelahmet

Ahmet Zore

Ali Değes

Ali Giret

Ali Karpit

Ali Kıyyık

Ali Major

Ali Patata

Ali Tillik

Arb1k Hasan

Arif Cinni

Aziz Beble

Aziz Horo

Fatma Han'e

Hüseyin Kuruş

İbiş Hükko

İsmet Kavvara

Kemel Beçciro

Kimyasal Mahmut

Mehamet Hayyeve

Menan Nikkil

Şihal More

Ömer Keltum

Reşit Külle 


\section{Sonuç}

Yapılan çalışmada "Yaptığı işten ya da meslekten dolayı verilmiş olan lakaplar 32, Fiziksel özellik, eksiklik ya da görünüşündeki farklılıklardan dolayı verilmiş lakaplar 52, Karakter ya da farklı bir özelliğinden dolayı verişmiş olan lakaplar 21, Soy, sülale, aile gibi aidiyet bildiren lakaplar 26, Anne ve baba ismi eklenerek verilmiş lakaplar 28, Soy, sülale, aile gibi aidiyet bildiren lakaplar 7, Gelmiş olduğu yerden (Köy, Kasaba, İlçe, İl, vb.) dolayı verilmiş lakaplar 11, Tek isim olarak verilmiş lakaplar 128, Arapçadan geçen abu (babasi) anlamında kullanılan lakaplar 2, Ad1, Soyadı ya da ünvanı kısaltılarak yapılmış olan lakaplar 1, Tanınmış bir şahsa benzetilerek takılmış lakaplar 4, Bir isimden sonra gelen lakaplar 26" toplamda lakaplarla ilgili 338 sözcük tespit edilmiştir. Kumlu ilçesi ve mahallelerinde derlediğimiz lakaplarla ilgili yaptığımız araştırmanın sonucunda, her ne kadar insanların resmi olarak adı soyadı olsa da içinde bulunduğu toplumun verdiği adın daha geçerli olduğu, daha net çağrışım yapma özelliğine sahip olduğu görülmüştür. Dikkati çeken bir durum da bir kişinin aldığı lakap sadece o kişiye ait olmamakta, çocuğuna, eşine, torununa da küçük ilavelerle lakap olmaktadır.

\section{Kaynakça}

Akçam, Z. (2015). XIX. Yüzyıl Kıbrıs Şer'iye Sicillerinde Lâkap Ve Unvanlar. Türkbilig, 29. S. 191-208.

Atlı, S. (2017). Manisa'nın Demirci İlçesindeki Lakaplar Üzerine Bir İnceleme. CÜ Sosyal Bilimler Dergisi. Cilt: 41. Say1: 1. S. 101-137.

Boyraz, Ş. (1988). Lakaplar Konusunda Bazı Dikkatler ve Bir Yöre Örneği. Türklük Bilimi Araştırmaları. VII. Sayı. s. 107- 138.

Bulukgiray, İ. (2021). Bingöl Zaza Köylerinden Emtağ'da Kullanılan Lakaplar Üzerine Bir İnceleme. Bingöl Araştırmaları Dergisi. S. 61-95.

Güllüdağ, N., Baş, H. (2019). 1452 Numaralı İzmit Şeriye Sicilinde Yer Alan Unvan Ve Lakaplar Üzerine Bir İnceleme. Anasay Dergisi. Y11:3 Say1:7. Sayfa: 73-104.

Koç, F. Hacı Bektâş-1 Veli'nin Eserlerinde Geçen Akrabalık Adları, Akademik Dil ve Edebiyat Dergisi. 4(2), S. 265-280.

Koraş, H. ve Shaikanova, G. (2021). Ey, Dünye Ey Romanında Kazaklardaki Lakap Takma, İsim Verme Üzerine Bir İnceleme. Karadeniz Uluslararas1 Bilimsel Dergi. Volume: 51, S.220-233.

Öztürk, J. (2016). Antakya Köylerinden Lakaplar. Hatay Tarihi Ve Kültürü Üzerine Araştırmalar-I. Mustafa Kemal Üniversitesi. Yayın No.59. S. 260-281.

Parlak Kalkan, G. (2020). Dil bilimsel açıdan lakaplar: Kilis yöresi örneği. RumeliDE Dil ve Edebiyat Araştırmaları Dergisi. S. 199-223.

Sevinç, F. (2019). Tezkirelerde Şair Tanıtımlarında Kullanılan Lakaplara Dair. Iğdır Üniversitesi Sosyal Bilgiler Dergisi. Say1 / No. 19. S. 309-342.

Şafak, A. (2017). Kan-Kapçıkay Destanını Diğer Destanlardan Ayıran Özellikler. Akademik Sosyal Araştırmalar Dergisi, Yı1: 5, Sayı: 41, S. 255-268

Şafak, A. (2021). Hatay-Kumlu İlçesinde Ağzında Kullanılan Kelimelerin Derlenmesi. Rimak International Journal of Humanities and Social Sciences. Volume:3, Issue:7 $\mathrm{P}: 226-236$.

Türk, O. (2017). Türkçe Öğretmenlerinin Konuşma İlgileri Ve Sinıf İçinde Kullandıkları Konuşma Dili Üzerine Bir Araştırma. Turkish studies, 12(6), 783-798.

Türk, O. (2020). Kültürel Miras Olarak Hayvanların Atasözlerimize Kattıkları Anlam Üzerine Bir Değerlendirme. Karadeniz Uluslararası Bilimsel Dergi, 11 (44), (320-334).

Türk, O. (2020). Orhon Yazıtlarında Kişi Ad1 ve Unvan Üzerine. Karadeniz Uluslararası Bilimsel Dergi, 48, p. (261-273)ISSN: 1308-6200 DOI Number: https://doi.org/10.17498/kdeniz.804780. 
Türk, O. (2021). Hamzaname'nin 72. Cildinde Yer Alan Arkaik Kelimeler. HİKMET-Akademik Edebiyat Dergisi [Journal of Academic Literature], 7/15, s. 135-148.

Türktaş, M., M. (2019). Türklerde Ad Verme İle İlgili Bazı Tespitler. TÜRÜK Uluslararası Dil, Edebiyat ve Halkbilimi Araştırmaları Dergisi. Yı1: 7, Sayı:17, Sayfa: 34-44.

www.islamansiklopedisi.org.tr, erişim tarihi: 20.12.2020

www.tdk.gov.tr, erişim tarihi: 20.12.2020

\section{KAYNAK KISSSILER}

İbrahim Geçen

Ahmet Kurumuş

Mustafa Geçen

Hakan Kurumuş

Ahmet Çarpar

Bülent Aydın

Mustafa Yayan

Abit Gezgin

Ergin Seçmen

Bülent Sabır

İsmet Şafak

Oktay Özdemir

Hilmi Seçmen

Bostan Yayla

Atilli Atasoy

Bilal Er

Ahmet Kirar

Derviş Acar

Ali Yildır

Cengiz Karalar

Fehmi Rüşvanlı 